\title{
Lumbar Spinal Hydatid Cyst with Intracanal and Paravertebral Invasion: A Rare Entity in an Unusual Location
}

\author{
Elias Antoniades ${ }^{1}$ Ioannis Magras ${ }^{1}$ Konstantinos Sapalidis ${ }^{2}$
}

${ }^{1}$ Department of Neurosurgery, AHEPA Hospital, Aristotle University of Thessaloniki, Thessaloniki, Greece

2 Department of General Surgery, AHEPA Hospital, Aristotle

University of Thessaloniki, Thessaloniki, 54621 Greece

Indian J Neurosurg 2017;6:151-152.

Hydatid disease is a parasitic infection associated with Echinococcus granulosus tapeworm. The spine may be affected in the context of hematogenous dissemination in $1 \%$ of the cases. ${ }^{1}$ According to its manifestation, hydatid disease is categorized as
1. Intramedullary
2. Extradural
3. Intradural extramedullary
4. Hydatid disease of the vertebra
5. Paravertebral ${ }^{2}$

An intradural disease without vertebral column involvement is extremely rare. ${ }^{2}$ Thoracolumbar spine (63.9\%) is the predominantly affected region, as Echinococcus typically inserts vascular segments of the spine. ${ }^{3}$

We aim to present an uncommon case of lumbar manifestation of hydatid disease, reviewing the literature as well.

A 65-year-old patient presented with lumboischialgie, progressive paraparesis $3 / 5$ of his right leg and $2 / 5$ of his left one accompanied by reflexes absence, hypaesthesia, and vegetative disorders. Symptoms were initially attributed to lumbar stenosis with unsuccessful conservative treatment having no amelioration by inclination. Plain radiographs of the lumbar spine were uneventful. Magnetic resonance imaging (MRI) of the lumbar spine revealed a multilobulated cystic formation with spatial dimensions $10 \mathrm{~cm} \times 4 \mathrm{~cm}$ between the second and fifth lumbar spine extending intracanally and compressing the dural sac leftward. The rest MRI neuraxis control was unremarkable. Computer tomographic (CT) scans of the chest and abdomen revealed no infiltration (-Fig. 1). The labor control revealed no eosinophilia, whereas indirect hemagglutination test for Echinococcus was positive in 1/256 dilution. Finally the echocardiogram was unremarkable too.
Address for correspondence Elias Antoniades, MD, Department of Neurosurgery, AHEPA Hospital, Aristotle University of Thessaloniki, Thessaloniki, 54621, Greece (e-mail: eliasantoniad@yahoo.gr).

With a raised suspicion of hydatid cyst, the surgical excision was warranted.

We performed a posterior laminectomy with resection of the intracanal cysts. Postoperative pain symptoms were relieved and muscle strengths restituted to $4 / 5$ right and 3/5 left, respectively. Hypaesthesia also retreated but unfortunately impaired micturition and defecation remained. Postoperative MRI control showed total resection. Albendazole was also administered for the following 4 months.

The mechanism of intracanally parasites seeding is attributed to hematogenic dissemination. ${ }^{4}$ The mechanism is imputed to the unique feature of vertebral plexus. Groen et al ${ }^{5}$ have divided it in their studies in three parts: the internal vertebral plexus surrounding the dura matter, the basivertebral veins of vertebral bodies, and the external vertebral plexus surrounding the column. The internal vertebral plexus communicates with the intraspinal and radicular veins that constitute valves, thus permitting a reflux and explaining the primary presence of hydatid cyst in the spine.

Symptoms of spinal disease usually manifest insidiously years after the primary infestation of cysts. Slow development of cysts over several years and the surrounding bone resistance support a rationale for this. Most patients refer a progressive low back pain with radiculopathy. ${ }^{6}$

MRI remains the diagnostic modality of choice. Findings suggestive of hydatid cyst on T1-weighted images include the isointense signal and hyperintensity on T2-weighted images. ${ }^{3}$

By deteriorating neurologic dysfunction, posterior laminectomy with intact cyst enucleation remains the horseshoe, which should also be combined with adjuvant anthelminthic therapy. ${ }^{7}$

Hanci et $\mathrm{al}^{8}$ and Prabhakar et $\mathrm{al}^{9}$ have also presented cases of lumbar spine hydatid cysts with deteriorating neurologic deficits treated with laminectomy and anthelminthic therapy with recession of deficits after decompression. received

May 4, 2017

accepted

July 3, 2017

published online

August 29, 2017
DOI https://doi.org/

10.1055/s-0037-1606309.

ISSN 2277-954X. (c) 2017 Neurological Surgeons' Society of India
License terms

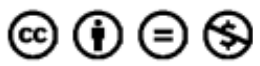




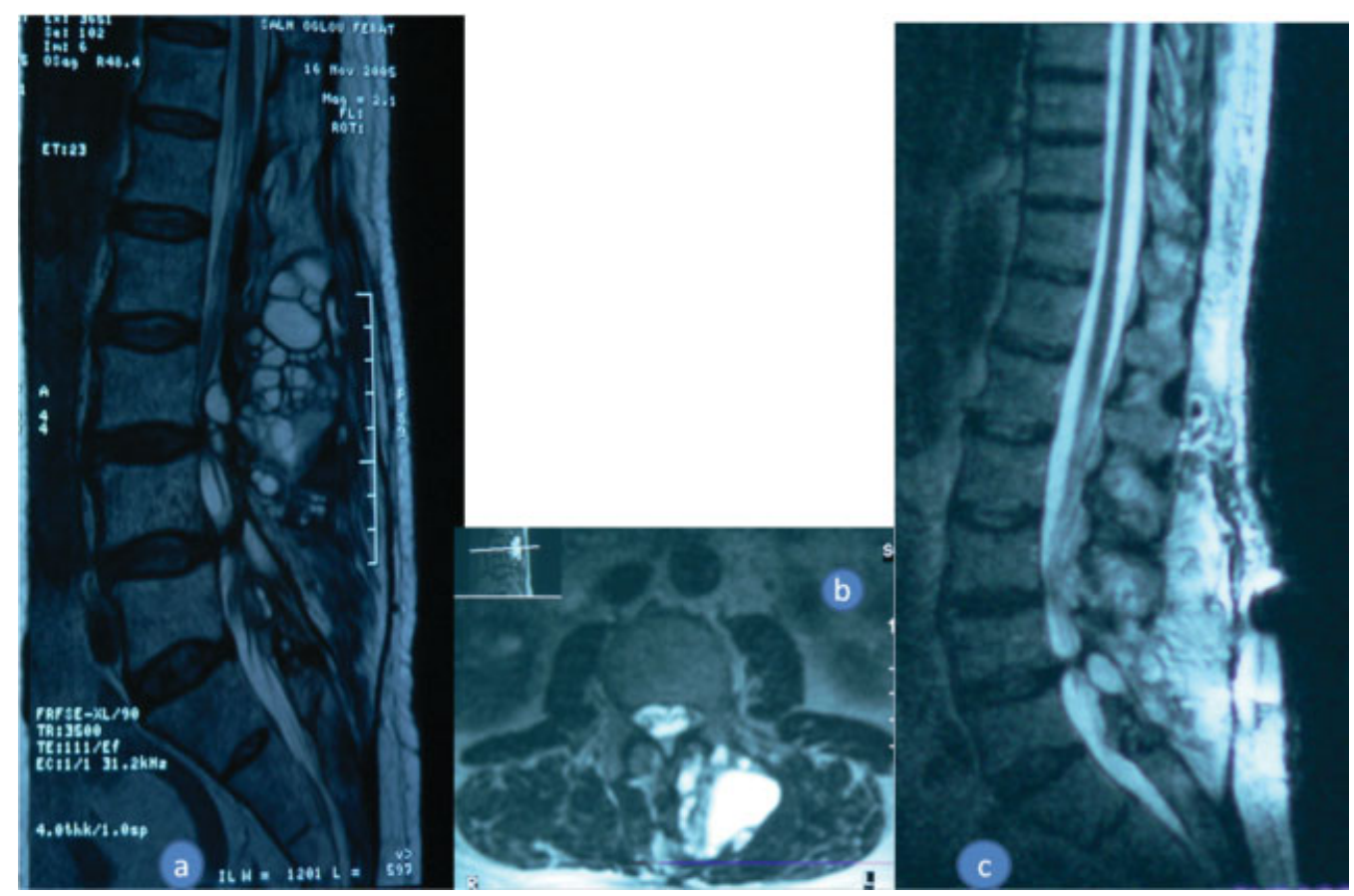

Fig. 1 (a) Preoperative sagittal sequences of MRI of lumbar spine, (b) axial sequences of the same examination, and (c) postoperative MRI T2-sagittal sequences of lumbar spine.

The unique features in this case were the initial deluding clinical and radiologic combination of findings regarding the extension of the lesion, extended intracanally and paravertebrally without significant vertebral body infiltration, and concomitant infection signs. Thus diagnostic suspicion should be raised by a cystic lesion type I or II according to Nabors' classification ${ }^{10}$ concerning hydatid disease as a rare but possible diagnosis.

\section{Note}

The patient has given his informed consent for publishing this case report.

\section{Funding}

None.

\section{Conflict of Interest}

None.

\section{References}

1 Fares Y, Khazim R, El Zaatari MM, Haddad GF, Barnes PR. Spinal hydatid disease and its neurological complications. Scand J Infect Dis 2003;35(6-7):394-396
2 Braithwaite PA, Lees RF. Vertebral hydatid disease: radiological assessment. Radiology 1981;140(03):763-766

3 Kafaji A, Al-Zain T, Lemcke J, Al-Zain F. Spinal manifestation of hydatid disease: a case series of 36 patients. World Neurosurg 2013;80(05):620-626

4 Kaen A, Lagares A, Perez-Nuñez A, Rivas JJ, Ramos A, Lobato RD. Intradural extramedullary spinal hydatidosis: case report. Neurocirugia (Astur) 2009;20(03):282-287

5 Groen RJ, du Toit DF, Phillips FM, et al. Anatomical and pathological considerations in percutaneous vertebroplasty and kyphoplasty: a reappraisal of the vertebral venous system. Spine 2004;29(13):1465-1471

6 Salduz A, Koyuncu LO, Dikici F, Talu U. [Long-term result of treatment for paraspinal and extradural hydatid cyst: a case report] [in Turkish]. Acta Orthop Traumatol Turc 2009;43(03): 267-271

7 Lam KS, Faraj A, Mulholland RC, Finch RG. Medical decompression of vertebral hydatidosis. Spine 1997;22(17):2050-2055

8 Hanci M, Aydingoz O, Tanriverdi T, Kocer N. Epidural hytatid cyst of the lumbar spine. A case report. Turkish J Spinal Surg 2001; 12:38-43

9 Prabhakar MM, Acharya AJ, Modi DR, Jadav B. Spinal hydatid disease: a case series. J Spinal Cord Med 2005;28(05): 426-431

10 Nabors MW, Pait TG, Byrd EB, et al. Updated assessment and current classification of spinal meningeal cysts. J Neurosurg 1988;68(03):366-377 